\title{
KARANG PANES DAN FENOMENANYA DALAM LONTAR BHAMA KRETIH
}

\author{
Oleh \\ I Made Dwitayasa \\ dwitayasa23@gmail.com \\ Universitas Hindu Negeri IGB Sugriwa Denpasar
}

Lontar Bhama Kretih memuat tentang proses pembangunan tradisional Bali dari baru mulai sampai akhir pembangunan. Selain itu juga dibicarakan ritual atau upacara yang digunakan dalam proses membangun tempat suci atau bangunan lainnya. Lebih lanjut lontar Bhama Kretih juga memuat tentang cara untuk menetralisisr areal pekarangan agar kehidupan manusia dapat harmonis, termasuk tata letak serta pengaruh dari areal pekarangan yang lazim disebut dengan sebutan karang panes.dari latar belakang di atas dapat dirumuskan permasalahan sebagai sebagai berikut: apa yang di maksud Karang panes dan bagaimana cara penaggulangannya menurut lontar Bhama Kretih?, bagaimana pandangan masyarakat Hindu Bali tentang Karang Panes?.

Dalam penelitian ini, peneliti menggunakan metode deskriptif kulaitatif dengan teori hermeneutik. Dari penelitian didapatkan bahwa yang dimaksud dengan karang panes adalah pekarangan yang mendapat pengaruh negatif, seperti: aura panas dalam pekarangan, para penghuni selalu ditimpa penyakit, rejeki yang tersendat-sendat, serta kehidupan para penghuninya tidak harmonis yang ditandai dengan adanya pertengkaran diantara penghuni. Untuk menetralisir atau menanggulangi Karang panes diharapkan membangun palinggih yang disebut dengan palinggih Indra Blaka atau Padma Andap sebagai stana Sang Hyang Indra Blaka. Selain berbentuk palinggih juga dalam bentuk ritual seperti Caru seperti caru Karang Panes, caru penganggihan, panca tawur, caru Rsi Ghana. Pandangan teologi masyarakat Hindu Bali, yaitu: Tuhan dalam manifestasinya sebagai Sang Hyang Durgha Manik, dipuja untuk melindungi manusia dari pengaruh unsur-unsur negatif. Karang angker diyakini berdampak negatif bagi penghuninya seperti penghuninya tertimpa sakit yang tanpa sebab, binatang piaraan yang mati secara tiba-tiba, dan sering terjadi pertengkaran diantara penghuni.

Kata kunci: Karang Panes; Bhama Kretih; 


\begin{abstract}
Lontar Bhama Kretih describes the traditional Balinese development process from the start to the end of development. In addition, it also discusses the rituals or ceremonies used in the process of building holy places or other buildings. Furthermore, the Bhama Kretih lontar also contains ways to neutralize the yard area so that human life can be harmonious, including the layout and influence of the yard area which is commonly referred to as Karang Panes. From the above background, the problem can be formulated as follows: What does Karang panes mean and how to deal with it according to the lontar Bhama Kretih? What is the view of the Balinese Hindu community about Karang Panes?

In this study, researchers used a qualitative descriptive method with hermeneutic theory. From the research, it was found that what is meant by hot coral is a yard that has a negative influence, such as: hot aura in the yard, the residents are always afflicted with disease, faltering fortune, and the lives of the residents are not harmonious which is marked by quarrels between the residents. To neutralize or overcome Karang Panes, it is expected to build palinggih which is called palinggih Indra Blaka or Padma Andap as Sang Hyang Indra Blaka's station. Apart from being in the form of palinggih, it is also in the form of rituals such as Caru such as caru Karang Panes, caru penganggihan, panca tawur, caru Rsi Ghana. The theological view of Balinese Hindu society, namely: God in its manifestation as Sang Hyang Durgha Manik, is worshiped to protect humans from the influence of negative elements. The haunted coral is believed to has a negative impact on its inhabitants, such as the occupants suffering from unexplained illness, pets that die suddenly, and frequent quarrels between residents.
\end{abstract}

Key word: Karang Panes; Bhama Kretih;

\title{
1. Pendahuluan
}

Kebudayaan merupakan wujud dari cipta, rasa, dan karsa manusia yang terimplementasikan dalam kehidupan sehari-hari dalam interaksi sosial. Kebudayaan masyarakat Bali merupakan salah satu aset kekayaan Pulau Bali yang luhur. Bali memiliki keunikan budaya yang dijiwai oleh agama Hindu, sehingga banyak para wisatwan asing berkunjung ke Pulau Bali, dengan tujuan untuk melihat dan menikmati keindahan Pulau Bali serta keunikan budayanya. Masyarakat Bali secara sadar maupun tidak sadar telah memiliki kebudayaan yang tinggi dan terbukti sampai sekarang Pulau Bali masih menjadi tujuan wisata dunia yang utama.

Dwijendra (2009) dalam Bukunya yang berjudul "Arsitektur dan Kebudayaan Bali Kuno" menjelaskan jika ditinjau dari arsitekturnya Desa Bali Aga mempunyai sejarah yang sangat panjang yaitu dari jaman Bali kuno, jaman datangnya Mpu Kuturan, adanya pengaruh Majapahit sampai jaman modern sekarang. Arsitektur Bali Aga diperkirakan ada pada jaman Bali kuno. Bentuk-bentuk rumah pada jaman ini sangat sederhana yang disebut dengan $k u b u$ serta memiliki banyak fungsi. Ciri khas arsitektur serta pemukiman masyarakat Bali Aga yaitu, rumah adatnya adalah rumah berupa rumah tampul roras (tiang dua belas), pola pemukimannnya yaitu dengan pola linier dengan struktur rumah berderet tanpa adanya 
tembok pembatas antara rumah yang satu dengan yang lainnya. disamping adanya komplek desa induk juga ada sub lingkungan yang berjauhan yang dihubungkan dengan jalan setapak.

Di dalam kehidupan budaya dan masyarakat, masyarakat Bali Aga memiliki ciri-ciri seperti kebersamaan atau gotong royong, hubungan yang sejajar antara anggota masyarakat, tidak adanya sistem kasta secara vertikal, susunan pengurusnya disebut dengan Hulu Ampad, sistem penguburan dengan bentuk kuburan batu (sarcopagus), memuja roh leluhur, adanya konsep luan dan teben. Di dalam sistem pengetahuan bersifat statis, yang dipengaruhi oleh dogmatisme yaitu menerima

Salah satu sumber yang mengatur tentang proses pembangunan bangunan tradisional Bali serta fenomenanya termuat dalam lontar yang disebut dengan lontar Bhama Kretih. Lontar merupakan sebuah karya sastra yang berasal dari pemikiranan penulis yang diyakini memiliki nilai yang sangat tinggi. Untuk melestarikan budaya atau hasil karya suatu bangsa sebagai generasi penerus tidak hanya dengan membersihkan lontar tersebut atau memberikan sesajen, tetapi bagaimana seseorang dapat menggali nilai atau makna yang terkandung dalam sebuah lontar. Secara garis besar lontar Bhama Kretih memuat tentang proses pembangunan tradisional Bali dari baru mulai sampai akhir pembangunan. Selain itu juga dibicarakan ritual atau upacara yang digunakan dalam proses membangun tempat suci atau bangunan lainnya. Lebih lanjut lontar Bhama Kretih juga memuat tentang bagaimana cara untuk menetralisir areal pekarangan agar kehidupan manusia dapat harmonis, termasuk tata letak serta pengaruh dari areal pekarangan.

Didalam lontar Bhama Kretih disebutkan berbagai pengaruh negative seperti: aura panas dalam pekarangan, para penghuni selalu ditimpa penyakit, rejeki yang tersendatsendat, serta kehidupan para penghuninya tidak harmonis yang ditandai dengan adanya pertengkaran diatara penghuni.

Dari latar belakang di atasa dapat dirumuskan permasalahan sebagai berikut:

1. Apa yang disebut dengan Karang panes dan bagaimana penanggulangannya menurut Lontar Bhama Kertih?

2. Bagaimana pandangan masyarakat Hindu Bali tentang Karang panes ?

Tujuan dari penelitian yang dilakukan adalah sebagai salah satu unsur pokok dari suatu perencanaan yang memerlukan sebuah dukungan serta alasan-alasan yang kuat dan mendasar guna tercapainya suatu hasil seperti yang diharapkan baik bagi peneliti maupaun bagi umat Hindu serta orang yang memerlukan hasi penelitian.Un tuk itu tujuan penelitian ini adalah: (1) Untuk mengetahui dan memaparkan tentang Karang panes dan cara penanggulangannya dalam Lontar Bhama Kretih; (2) Untuk mengetahui sejauh mana pandangan umat Hindu yag ada di Bali tentang kareng Panes yang terdapat dalam Lontar Bhama Kretih;

Secara teoretis penelitian ini diharapakan memberikan manfaat diantaranya dapat memperluas pengetahuan serta pengembangan pemikiran bagi masyarakat Hindu yang ada di Bali. Selain itu penelitian ini dapat menumbuhkan minat bagi para peneliti lainnya seperti teologi, filsafat, sastrawan, serta budayawan dan yang lainnya untuk menguji serta meneliti 
lagi tentang karya sastra yang memiliki nilai yang adi luhung. Secara praktis penelitian ini diharapkan dapat memberikan kontibusi berupa :

1. Dapat dijadikan suatu pegangan dan sebagai sumber bacaan bagi umat Hindu terutama yang ada di Bali terkait dengan Karang panes serta penanggulangannya dalam kehidupan umat Hindu

2. Melalui penelitian ini diharapkan masyarakat dapat memperdalam pengetahuannya tentang Karang panes yang terdapat dalam Lontar Bhama Kertih

3. Selain sebagai sumber bacaan bagi umat Hindu, dengan hasil penelitian ini masyarakat Hindu dapat memberikan penjelasan tentang apa yang dimaksud Karang panes serta bagaimana cara penanggulangannya.

Penelitian ini menggunakan metode deskriptif kualitatif dengan teori hermeneutik. Dari penelitian didapatkan bahwa yang dimaksud dengan karang panes adalah pekarangan yang mendapat pengaruh negative seperti: aura panas dalam pekarangan, para penghuni selalu ditimpa penyakit, rejeki yang tersendat-sendat, serta kehidupan para penghuninya tidak harmonis yang ditandai dengan adanya pertengkaran di antara penghuni. Untuk menetralisir atau menggulangi Karang panes diharapkan membangun palinggih yang disebut dengan palinggih Indra Blaka atau Padma Andap sebagqai sthana Sang Hyang Indra Blaka. Selain berbentuk palinggih juga dalam bentuk ritual seperti Caru seperti caru Karang Panes, caru penganggihan, panca tawur, caru Rsi Ghana. Pandangan masyarakat Hindu Bali tentang Karang panes yaitu pandangan Teologi. Dalam kontek pemahaman teologi, Tuhan dalam manifestasinya sebagai Sang Hyang Durgha Manik kalau dilihat dalam fungsi teologi mempunyai suatu peranan yang sangat penting, karena Sang Hyang Durgha Manik merupakan perwujudan manifestasi Tuhan untuk melindungi manusia dari unsure-unsur negative. Pandangan Angker yaitu Karang angker diyakini akan berdmpak negatif bagi penghuninya seperti penghuninya tertimpa sakit yang tanpa sebab, binatang piaraan yang mati secara tiba-tiba, dan sering terjadi pertengkaran di antara penghuni.

Kajian Teoritis/atau Tinjuan Pustaka

\section{Hasil Penelitian}

Penelitian pada hakikatnya merupakan suatu usaha untuk menemukan, mengembangkan, dan menguji kebenaran suatu pengetahuan dengan menggunakan metodemetode ilmiah. Para pakar mengemukakan pendapat yang berbeda dalam merumuskan batasan penelitian atau penyelidikan terhadap suatu masalah, baik sebagai usaha mencari kebenaran melalui pendekatan ilmiah. Secara umum, penelitian diartikan sebagai suatu proses pengumpulan dan analisis data yang dilakukan secara sistematis dan logis untuk mencapai tujuan tertentu. Pengumpulan dan analisis data menggunakan metode-metode ilmiah, baik yang bersifat kuantitatif dan kualitatif, eksperimental atau noneksperimental, interaktif atau non interaktif.

Penelitian dapat pula diartikan sebagai cara dan proses penemuan melalui pengamatan atau penyelidikan yang bertujuan untuk mencari jawaban permasalahan atau 
persoalan sebagai suatu masalah yang diteliti. Kerlinger (1986) mengemukakan, penelitian ialah proses penemuan yang mempunyai karakteristik sistematis, terkontrol, empiris, dan mendasarkan pada teori dan hipotesis atau jawaban sementara. (http://lyanasikumbang.blogspot.co.id/2013/03/pengertian-tujuan-dan-fungsi penelitian.html diakses tgl 23 September 2016)

Dalam penelitian ini peneliti dapat menemukan data bahwa yang disebut dengan karang panes adalah suatu areal yang memiliki sifat negatif. Menurut Lontar Bhama Kretih, Karang panes dapat memberikan pengaruh negatif bagi para penghuninya seperti, sakit yang tidak dapat disembuhkan secara medis, sering terjadi pertengkaran dalam keluarga, binatang piaraan tertimpa penyakit dan menyebabkan kematian. Yang tergolong Karang panes seperti : karang kelingkuhan, karang kuta kubanda, sula nyupi, tumbak rurung, tumbak tukad, nampih bale banjar, namping pempatan, ngulonin pura, karang yang berdiri di atas tanah kuburan. Selain disebabkan oleh pengaruh dan tata letak areal, Karang panes dapat disebabkan atau diakibatkan oleh tumbuhan seperti pohon enau yang bercabang, pohon kelapa yang bercabang. Karang panes juga dapat disebabkan oleh binatang seperti binatang yang beranak hanya satu (manak tunggal). Untuk menetralisir atau menggulangi Karang panes diharapkan membangun palinggih yang disebut dengan palinggih Indra Blaka atau Padma Andap sebagqai sthana Sang Hyang Indra Blaka. Selain berbentuk palinggih juga dalam bentuk ritual seperti caru Karang Panes, Caru Penganggihan, Panca Tawur, Caru Rsi Ghana.

\subsection{Gambaran Umum Lontar Bhama Kretih}

Lontar Bhama Kretih merupakan salah satu lontar Tattwa di Bali. Lontar Bhama Kretih berisi penjelasan tentang areal pekarangan (karang) yang memiliki sifat atau keadaan yang baik (positif) dan keadaan yang buruk (negatif) pada keempatan ini peneliti mempergunakan acuan yaitu salinan lontar Bhama Kretih koleksi kantor Departemen Agama Kabupaten Gianyar, di mana pustaka tersebut merupakan koleksi pribadi peneliti. Salinan Lontar Bhama Kretih ditulis di atas sebuah kertas dengan jumlah halaman 71 lembar, panjang $21 \mathrm{~cm}$ dan lebar $18 \mathrm{~cm}$. pada bagian awal dijelaskan tentang judul lontar yaitu Bhama Kretih, selanjutnya asal lontar yaitu milik Ida Pedanda Manuaba dari Griya Sibang Kaja, Kecamatan Abiansemal, Kabupaten Badung, Bali. Pada bagian manggala ditulis dengan kalimat Om Swastyastu, yang dilanjutkan dengan isi lontar dimaksud. Pada bagian kolofon ditandai dengan keterangan penulis lontar yang asli dengan kalimat "duk puput puniki wawu mabersih, wawu 12 tiban kirang tigang sasih, tanggal 15 Juli 1961. Selanjutnya disi pula pada saat selesai lontar tersebut disalin yaitu dengan kalimat “ Denpasar, 31 Januari 1978. Pada pokok atau isinya lontar Bhama Kretih membahas dan menjelaskan tentang proses pembangunan tempat suci, baik buruknya pekarangan atau yeng lebih dikenal dengan sebutan Karang panes beserta proses penanggulangannya. 


\subsection{Karang panes Menurut Lontar Bhama Kretih}

Setiap orang ingin hidup bahagia baik lahir maupun batin. Untuk mencapai kehidupan yang bahagia sangatlah sulit, karena ukuran bahagia bagi setiap orang berbeda. Berkaitan dengan bahagia Agama Hindu menurut tradisi Bali, tidak berasal dari uang ataupun materi. Kebahagian juga dapat terwujud melalui alam sekitar. Tri Hita Karana sebagai landasan kehidupan yang harmonis hubungan manusia dengan Tuhan yang dilaksanakan melalui cara berbakti kepada Tuhan beserta manifestasinya melalui berbagai kegiatan keagamaan. Hubungan manusia dengan manusia dilakukan dengan cara melakukan hubungan yang harmonis dengan sesama dalam masyarakat, dan hubungan manusia dengan alam dan lingkungan dilaksanakan dengan melestarikan alam termasuk areal pekarangan rumah. Pembuatan rumah dalam konsep rumah tradisional Bali sangat berbeda, baik tata cara, bentuk, posisi, maupun jenis bangunannya. Keyakinan umat Hindu yang ada di Bali mengenai posisi rumah tidak boleh sembarangan. Pemilihan tempat sebagai areal pekarangan sangatlah penting guna keharmonisan anggota keluarga.

Ajaran agama Hindu dengan konsep kesemestaan alamnya senantiasa menekankan betapa perlu dan pentingnya diciptakan suatu kondisi harmonis antara manusia dengan Tuhan, manusia dengan manusia, dan manusia dengan lingkungan. Kondisi yang harmonis itulah yang mengantarkan umat Hindu pada tujuan hidupnya, yaitu: jagadhita dan tujuan akhirnya adalah moksa. Berpijak dadi pandangan demikian maka terhadap penggunaan suatu lingkungan patut juga memperhatikan segi-segi yang diyakini turut membuat kondisi harmonis. Karena itu lontar Ling Ira Bhagawan Wiswakarma telah menyuratkan perihal pekarangan atau tanah yang baik dan yang tidak baik dipergunakan untuk mendirikan suatu bangunan, baik perumahan, gedung, kantor, sekolah, tempat suci, dan lain-lain.

Pekarangan yang baik digunakan antara lain disebut: di Timur (Purwa) menemu labha (penghuninya akan mendapat untung), di utara: paribhoga wredhi (sejahtera dan bahagia), palemahan asah: sedang-sedang saja, palemahan inang: ceria dan asri serta berisi manik, palemahan mambu: keasihin (dikasihi sahabat) (http://suryadistira.blogspot.co.id/2008/05/apaciri-ciri-karang-panes.html)

Selanjutnya pekarangan yang tidak baik dipergunakan lazim disebut sebagai "Karang Panes" dengan ciri-ciri berupa risiko yang diterima oleh si penghuni tanah tersebut yaitu: sering jatuh sakit, marah-marah tidak karuan, mengalami kebingungan, mudah bertengkar, dan sejenisnya. Ada pun jenis-jenis tanah yang tergolong Karang panes ini di antaranya:

1. yan hana karang tunggal pemesuan mangaleking, ala nyakitin karubuhan jalan ngaran. Artinya jika ada bebrapa pekarangan namun memiliki satu pintu keluar itu sangatlah tidak baik yang disebut mangaleking ini berbahaya bagi yang menhuni pakarangan tersebut.

2. Yan hana karang tumbak rurung sandang lawe ngaran, gering maderes, yan karang kalingkuhan rurung sula nyupi ngaran ala, yan karang apit rurung muah apit jalan kuta kubanda ngaran. Artinya: jika ada pekarang seperti pekarangan tusuk sate itu disebut dengan sandang lawe yang menyebabkan sakit tiada hentinya bagi penghuni rumah 
tersebut, lalu jika ada rumah yang diitari oleh jalan maka itu disebut dengan kuta kubanda sangat berbahaya bagi penghuninya.

3. Muah yan hana umah naggu nora metabeng umah ring arepniya ngaran ala. Artinya jika ada rumah di batas desa namun didak ada rumah didepannya sebagai pendamping maka itu disebut dengan Karang panes yang berbahaya bagi penghuninya.

4. Yan hana wang metunggalan sanak mengapit jalan umahniya, sang tunggal naga purus sandang lawe ngaran ala dahat sang maumah, iriya amadha-madha bhatara ngaran. Artinya: jika ada seseorang yang masih bersaudara kandung yang tinggalnya berseberangan jalan yang masih satu garis keturunan itu yang disebut dengan sandang lawe berbahaya bagi yang menempati rumah tersebut dan itu disebut juga melawan dewa.

5. Muah yan umah mepemesuan dadua ala dahat boros wong ngaran. Artinya jika ada satu pekarangan yang memiliki dua pintu keluar yang sama itu disebut dengan boros wong atau orangnya selalu akan boros.

6. Muah ne tan wenang genahin umah lwirnya: karang wit pura, wit ibu, sema pebajangan, wit penyadnyan sang brahmana, karang lebon amuk karang genah wong mati megantung, yang sampun ping tiga kalebon amuk tan wenang genahin umah ala dahat. Artinya lagi-lagi yang tidak patut dibuat bangunan rumah adalah tanah bekas Pura, tanah bekas pemujaan leluhur, tanah bekas kuburan, bekas pertapaan/pemujaan orang suci, tanah bekas orang saling bunuh, tempat orang yang mati gantung diri, bila sampai tiga kali tertimpa pembunuhan maka sama sekali tidak boleh dibangun perumahan, sangat berbahaya.

7. Malih ingon-ingon patik wenang wenang, metu salah rupa ika cirin gumi rusak muah Karang Panes, asu bangkung manak tunggal, cirin panes karang ika, wenang hanyut buta salah wetu ngaran. Artinya jika ada binatang lahir dengan wajah/rupa yang berbeda itu tanda kehancuran, dan Karang Panes, jika ada anjing dan babi betina yang beranak satu itu bertanda Karang Panes, mestinya harus dilarung kelaut dengan upacara untuk melarung keburukan karena disebut bhuta salah wetu.

8. Muah bumi sayongan ketiban kuwug-kuwug, panes bhumi ika, ring pekarangannya metu kukus, panes karang ika, muah karang tumbak rurung, tumbak jalan, tumbak tukad, namping marga, pempatan, pura, namping bale banjar mekdinya ngulonin banjar panes karang ika. Artinya jika ada asap keluar dari tanah pekarangan, ada sejenis pelangi pada malam terang bulan itu pertanda kurang baik, jika ada pekarangan tusuk sate baik oleh gang atau jalan besar atau sungai berdampingan dengan perempatan, dengan pura, balai banjar atau berada di hulu maka itu disebut dengan Karang Panes.

9. Malih bawi baberasan satha asaki ring salu muang tabuan sirah dipakubonannya, lelipi masuk ring pakubonannya panes karang ika,muah pakubwania mebaha...Artinya jika pada saat menyembeleh babi dagingnya menyerupai butiran-butiran beras itu pertanda Karang Panes, begitu pula ada binatang bersenggama di dalam rumah, bila ada tawon bersarang di dalam rumah, ada ular masuk rumah itu pertana pekarangan panes.

10. Yan hana umah puwun, lakare taler kari ingangge pada cacade lawan nagasesa tan pegat milara, muah yan ana bale pungkat malih jujukang sejabining gebug lindu mageng maka gumi pada cacde ring baleen puwun lakare...... artinya jika ada rumah yang dari bekas kebakaran itu sama halnya seperti memelihara ular yang berbisa yang menyebabkan 
penghuninya tidak henti-hentinya mendapatkan penderitaan. Begitupula jika ada bangunan rumah ynag roboh kemBali didirikan kecuali dirubuhkan oleh gempa sama buruknya dengfan menggunakan kayu bekas kebakaran.

11. Muah yan ana bale adegannya masuk ring legungane balu makabun ngaran ala, yan ana bale matrestes bunter adegannya sami cacad, dongkang makehem ngaran tan wenang ingangge ala dahat, muah yan ana bale terajagan magrantang maileh cacad, dongkang makehem ngaran ala......artinya jika ada tiang bale yang melewati lambing itu dinamakan balu mekabun yaitu buruk sekali. Jika ada bale yang seluruh tiangnya bundar tanpa sudut itu disebut bangunan cacad yang bernama dongkang makehem tidak baik ditempati dan sangat berbahaya. Lagi jika ada bale tanpa berbentuk limas di diisi emper itu namanya bangunan cacad yang disebut dongkang mangerem dan sangat buruk dampaknya bagi penghuni rumah tersebut.

12. Yan ana tayu rempak, pungkat muang punggel tan pakarana pada panese tan pegat amilara, muah nyuh macarang, buah macarang, jaka macarang, ental macarang, biyu mecarang, muwah wetunya kembar tunggal panese kadi kagni bhaya, kapanca bhaya........... artinya jika ada pohon yang rempak, roboh, patah tanpa ada sebabnya itu disebut panas tidak henti-hentinya mendapatkan bahaya. Kalau ada pohon kelapa yang bercabang, pohon pinang bercabang, pohon enau yang bercabang, pohon rontal bercabang, pohon pisang bercabang dan tumbuhnya kembar sama bahayanya (panasnya) seperti kagni bhaya (kebakaran) dan kepanca bhaya (lima jenis pembunuhan).

13. Muah yan ana pakubuwan keni ketampig taru rebah karipu bhaya ngaran panes, yan ana sanggah pungkat muwang jineng, pawon pungkat tan pakrana, muwang katiben amuk, kalebon amuk panca bhaya ngaran panes, yan ane ngawe pungkate panes karang ika, kewala pungkat tan wenang ingangge, wenang gentosin lakarne sami,...........artinya jika ada pekarangan atau bangunan tertimpa kayu yang roboh itu namanya karipu bhaya juga disebut Karang Panes, jika ada tempat suci yang roboh, jineng, dapur yang roboh tanpa sebab atau karena diamuk orang atau dimasuki oleh orang yang sedang mengamuk namanya panca bhaya artinya panas, jika ada yang menyebabkan robohnya juga disebut Karang Panes, setiap ada bangunan yang roboh tidak bisa digunakan kembali dan wajib diganti seluruh bahan bangunannya.

14. Muah yan ana wong mentik ring babataring salu wong bhaya ngaran panes, yan ana lulut metu ring pakarangan kalulut bhaya ngaran panes, yan ana getih kentel ring pakarangan muang sumirat ring umah ring pakubuwan, tan pakarana karaja bhaya ngaran. Artinya kalau ada cendawan yang tumbuh di bawah kolong tempat tidur itu dinamakan wwong bhaya artinya juga panas, jika ada lulut (sejenis binatang seperti cacing kecil-kecil) muncul dipekarangan, itu namanya kelulut bhaya yang menyebabkan panas pekarangan. Begitupula jika ada darah kental dipekarangan yang tercecer disekitar rumah yang tidak ada sebabnya itu dinamakan keraja bhaya.

15. Yan hana tabwan sirah, tabwan kulit mwang nyawan, ring salu, ring pahumahan, ring kubwan, pateh panese. Yan ring lumbung, ring kamulan hayu ika. Muwah yan hana ingoningon, patik, wenang - wenang, salu rupa wetune, panes karang ika, wenang rarung ka segara, tugel gulena, kawandaniya rewekan ring rwi walatung, talining dening budur, bwangen ring payonidi. Raris glarana Panca Tawur. Yan hana taru salah pati mwang manusa salah pati ring 
pekarangan, panes karang ika. Mwah salwiring jadma salah pati, hanuli pejah, sagenah genahniya pejah, ika tan wenang malih hantuk akna maring pagenahan, hala dahat, hanuli pendhem ring serta, nganut linging sastra bwana purana. Mangkana kramanya

Dari pemaparan hal tersebut di atas beraneka macam cirri-ciri yang dapat di cermati apakah suatu areal pekarangan itu panas atau tidak dalam artian suatu pekarangan layak atau tidak untuk ditempati. Terhadap jenis pekarangan/tanah di atas bisa saja digunakan asal sudah melalui upacara upahayu halaning palemahan seperti Caru Karang Panes. Tetapi akan lebih rahayu lagi jika tidak dipergunakan. Selain hal tersebut di atas dalam lontar Bhama Kretih juga disebutkan sabda dari Bhagawan Wiswakarma bahwa pekarangan atau tanah yang baik dan yang perlu dihindari untuk dibangun baik sebagai perumahan, perkantoran, sekolah, tempat suci dan lain-lain. Pekarangan yang baik menurut lontar tersebut antara lain:

1. Maпетu Labha yaitu areal Lebih tinggi di Barat/ miring ke timur (dari arah pusat kota atau dari arah jalan raya). Disebut manemu labha di mana sinar matahari tidak terhalang sejak pagi sampai sore, membawa keberuntungan dan umur panjang.

2. Paribhoga Wredhi yaitu tanah yang miring ke Utara, membawa kemakmuran yang melimpah bagi penghuninya.

3. Palemahan Asah yaitu tidak ada keistimewaan artinya biasa-biasa saja, namun dengan syarat: sinar matahari, udara dan air tersedia cukup tidak terhalang apapun.

4. Palemahan Inang yaitu ketika berada di atas tanah itu perasaan damai, tentram dan hening, walaupun lokasi itu tidak memenuhi persyaratan seperti nomor 1,2,3 di atas, disebut "dewa ngukuhi", membawa ketentraman bathin dan kedamaian.

5. Palemahan Mambu yaitu Tanah berbau cabe/bumbu dapur ketika dicongkel sedalam 30 $\mathrm{cm}$, disebut sihing kanti sangat baik karena akan mempunyai banyak sahabat.

Pekarangan yang harus dihindari atau dalam bahasa Bali sering disebut dengan "Karang Panes" biasanya ditandai dengan adanya kejadian/musibah yang menimpa anggota keluarga, misal: sering sakit, marah-marah tidak karuan, mengalami kebingungan (linglung), mudah bertengkar dan lain-lain. Karang panes atau pekarangan yang tidak baik untuk dijadikan tempat tinggal, antara lain:

1. Karang Karubuhan, pekarangan yang berhadap-hadapan atau berpapasan dengan perempatan atau pertigaan atau persimpangan jalan.

2. Karang Sandanglawe, pekarangan yang pintu masuknya berpapasan dengan pekarangan milik orang lain.

3. Karang Kuta Kabanda, pekarangan yang diapit oleh 2(dua) ruas jalan.

4. Karang Sula Nyupi, pekarangan yang berpapasan dengan jalan raya atau numbak marga atau numbak rurung.

5. Karang Gerah, pekarangan yang terletak dihulu Pura/Parahyangan.

6. Karang Tenget, pekarangan bekas pekuburan, bekas pura atau bekas pertapaan.

7. Karang Buta Salah Wetu, pekarangan dimana pernah terjadi kejadian aneh misal: kelahiran babi berkepala gajah, pohon kelapa bercabang, pisang berbuah melalui batangnya.

8. Karang Boros Wong, pekarangan yang memiliki dua pintu masuk sama tinggi dan sejajar.

9. Suduk Angga, pekarangan yang dibatasi oleh pagar hidup (tanaman) dimana akarakarnya atau tunasnya masuk ke pekarangan orang lain. 
10. Karang Kalingkuhan, Pekarangan yang dikelilingi tanah atau rumah milik satu orang (https://pduarsana.com/tag/karang-panes diakses tanggal 2 Agustus 2016).

\subsection{Cara Menanggulangi Karang Panes}

Ajaran agama Hindu dengan konsep alam semestanya senantiasa menekankan betapa perlu dan pentingnya diciptakan suatu kondisi harmonis antara manusia dengan Tuhan, manusia dengan sesamanya dan manusia dengan lingkungannya. Kondisi harmonis itulah yang akan mengantarkan umat Hindu untuk mencapai tujuan Hidupnya yaitu Jagadhita dan Moksha. Untuk itulah pemilihan sebuah pekarangan untuk dibangun rumah/tempat tinggal (palemahan/pekarangan) hendaknya memperhatikan hal-hal yang diyakini akan turut berperan menciptakan kondisi yang harmonis. (https://paduarsana.com/tag/karangpanes/diakses tanggal 2 Agustus 2016).

Jika dalam suatu kondisi terpaksa menampati atau membangun rumah yang termasuk "Karang Panes" disarankan membuat Padma Capah sebagai stana Sang Hyang Indrablaka dan pada hari yang tergolong rerahinan (hari suci), penghuninya menghaturkan sesaji untuk memohon keselamatan dan agar terhindar dari pengaruh buruk pekarangan rumah tersebut. Untuk lebih jelasnya berikut peneliti tuliskan penanggulangan Karang panes menurut lontar Bhama Kretih sebagai berikut.

\subsubsection{Padma Andap Sebagai penaggulangan Karang Panes}

Di dalam lontar Bhama Kretih dijelaskan berbagai jenis Karang Panes, yaitu suatu areal pekarangan yang memiliki sifat negative (buruk) yang disebut dengan Karang Panes. Ini mengakibatkan penghuni pekarangan tersebut tertimpa berbagai bencana seperti, sakit yang tidak wajar, sering bertengkar, kekurangan artha benda (uang dsb) meskipun sudah bekerja dengan tekun (kos boros). Di dalam lontar Bhama Kretih disebutkan sebagai berikut:

.....Iki Pamanes Karang salwiring panes, sane ngadakang panes karang, lwirnia, kapanjingan gelap mwang puhun, wenang ngadegang linggih Padma Andap, palinggih Sang Hyang Indra Blaka, tan pegat hamanggih lara bhaya yadin ping dasa caruning tan sidha purna dening caru ika. Apan Sang Hyang Indra Blaka dadi Sang Hyang kala maya dadi kala desti. Mangkana kajarnia.

Dari lontar tersebut di atas dapat dijelaskan bahwa banyak sekali yang menyebabkan Karang panes salah satunya adalah pekarangan pada waktu siang hari kelihatan gelap yang diakibatkan asap yang muncul dari dalam tanah pekarangan tersebut. Ada juga rumah yang kebakaran ini harus membuat yang dimaksud dengan bangunan Padma Andap atau yang disebut dengan Padma Capah. Masyarakat Hindu yang ada di Bali mendirikan bangunan ini di sudut Barat Laut pekarangan menghadap ketengah. Bangunan ini sebagai sthana Sang Hyang Indra Blaka sehingga bangunan ini juga dikenal dengan bangunan Indra Blaka.

Menurut Subrata (wawancara, tanggal 12 Agustus 2016) bangunan Indra Blaka sangat penting di bangun pada areal yang dianggap memiliki aura yang negatif atau yang lebih dikenal dengan sebutan Karang Panes. Lebih lanjut dipaparkan bahwa selain memiliki sebutan Sang Hyang Indra Blaka beliu juga memiliki sebutan Sang Hyang Dhurgha Maya. Selain dibangun di dalam pekarangan palinggih Indra Blaka juga dibangun pada sudut pekarangan yang 
dianggap mendapatkan pengaruh negative. Seperti contohnya karang tumbak rurung atau tusuk sate, maka pada pekarangan yang kena tusuk sate wajib membangun Padma Andap atau Padma Capah sebagi sthana Sang Hyang Indra Blaka untuk meteralisir area pekarangan dimaksud. Dalam lontar Bhama Kretih disebutkan:

Yan hana karang katumbak rurung, tumbak jalan, katumbak labak, katumbak jalinjingan mwang tukad, katumbak pangkung, panes karang ika, Sang Hyang Kala Durga hanglaraning, wenang ngadegang padma alit, palinggih Sang Hyang Durgamaya.

Palinggih Indra Blaka juga wajib di bangun di sudut pekarangan yang disebut karang kalingkuhan rurung/ sula nyupi, karang apit rurung muah apit jalan / kuta kubanda harus membangun Padma Andap/Padma Capah sebagai sthana Sang Hyang Indra Blaka. Selain itu jika ada rumah yang berdampingan dengan Pura, Balai Banjar apalagi pekarangan tersebut berada di hulunya wajib juga membangun bangunan yang disebut palinggih Sang Hyang Indra Blaka.

\subsubsection{Caru Sebagai Penanggulangan Karang Panes}

Menurut keyakinan masyarakat Hindu yang ada di Bali bahwa area suatu pekarangan memilki perbedaan dengan masayarakat hindu yang ada di luar Bali. pembangunan rumah sebagai tempat tinggal mempergunakan ukuran sesuai dengan ukuran perhitungan Bali yang disebut dengan Asta Bhumi dan Asta Kosala-Kosali. Karang panes selain diakibatkan oleh letak atau lokasi tanah juga diakibatkan oleh kesalahan pada waktu mengukur suatu pekarangan. Seperti disebutkan di atas bahwa untuk menanggulangi yang disebut dengan Karang panes yang diakibatkan oleh letak pekarangan yang kurang baik, maka dibuatkan bangunan yang disebut dengan Padma Andap atau Padma Capah. Selain itu dalam lontar Bhama Kretih juga disebutkan upacara dan upakara dalam menaggulangi Karang panes yang disebut dengan caru, seperti tersebut dibawah ini :

........ Iki Caru Pengasih Bhutanga, pamahayu pekarangan, pamahayu sanggar pomahan. Umaparania, ca, tumpeng putih kuning den agung, hinideran sarwa sekar, rakania putih kuning, canang genten, iwaknia satha sudhamalagrungsang kumatandhang mapanggang, muwah itik putih ginuling, mawadah dulang anyar, marajah surya candra. Wus minantra pendhem tengahing natar. Phalania, yan hana wong hakriya hala, salwiring tuju tluh taranjana, leyak prakasa, bhuta kala dengen, mari denia dewa sih bhuta wedhi. Mangkana kramania, haywa sang pandhita mapi tan weruh sastra $i k i$, apan sinilib se Sang Hyang licin, nging haja wera, rahasya temen.

Mwah yan hana kayu rempak, pungkat mwang punggel tan pa karana, pada panese, tan pegat hamilara. Mwah nyuh macarang, bwah macarang, jaka macarang, ntal macarang, byu macarang, mwang wetunya kembar, tunggal panese, kadi kagenibhaya nga, panes Yan hana sanggah pungkat mwah jineng, pawon, pungkat tan pakarana, nwang katiben amuk, kalebon amuk, panca bhya nga, panes. Yan hana hanggawe pungkate, panes karang ika, kewale cacad, tan kawenang malih ingagge, wenang gentpsin lakare sami. Muwah yan hana wong mentik ring babatar ing salu, wong bhaya nga, panes. Yan hana lulut metu ring pekarangan, kalulut bhaya nga, panes. Yan hana getih kentel ring pekarangan, mwang sumirat ring humah ring pakubwan tan pakarana, karaja bhaya nga. Yan hana samangkana, apang sampunang langkungan ring petang dasa dina, mangda puput macaru, dados caru ika halitan. Yan langkung ring petang dasa dina, hageng nagih caru hika kanget akna.

Lontar Bhama Kretih menyebutkan bahwa jika ada tanda-tanda seperti tersebut di atas hendaknya penghuni pekarangan membuat upakara berupa banten caru dan diharapkan 
jangan sampai pelaksanaannya lebih dari tiga hari sejak gejala dimaksud diketemukan. Jika pelaksanaan caru kurang dari tiga hari maka upacara dan upakarannya lebih sederhana atai keci misalnya caru ayam brumbun, prayascita durmanggala, beyakaonan. Jika mampu membuatnya buatlah caru yang disebut dengan caru pengasih bhuta. Ini dimaksudkan agar seluruh unsur alam (bhuta) melindungi penghuni pekarangan tersebut. Namun jika upacara dan upakara digelar lebih dari tiga hari sejak gejala tersebut dilaksanakan maka upacara dan upakaranya lebih besar karena diibaratkan penyakit sudah mewabah, ini memerlukan upakara yang lebih besar seperti caru panca sata dan yang sejenisnya.

Menurut Wikarman (1998:19-22) menyebutkan bahwa caru palemahan adalah upacara untuk mengharmoniskan areal pelataran atau wilayah hunian yangt dilaksanakan berdasarkan waktu baik secara rutin maupun secara insidensial. Caru secara rutin dilaksanakan secara terus menerus seperti kajeng keliwon, piodalan yang dislaksanakan tetap pada kurun waktu tertentu. Sedangkan caru yang bersifat insidensial dilaksanakan hanya sewaktu-waktu apabila diperlukan dengan tujuan untuk mengharmoniskan atau mengembalikan keseimbangan areal akibat sesuatu yang tidak wajar seperti sakit yang mewabah menimpa penghuninya, terjadi pembunuhan atau bunuh diri.

Selain itu menurut Wikarman membagi caru pelemahan seperti Caru Karang panes dan caru kegeringan. Caru Karang panes dengan cirri-ciri sakit tak henti-hentinya yang berakibat kematian, binatang peliharaan selalu terkena penyakit, ataupun disebabkan oleh keadaan areal pekarangan yang tidak sesuai dengan ukuran (sikut) termasuk Karang Panes. Ini wajib diupacarai sesuai dengan petunjuk sastra.

\subsubsection{Panca Tawur Sebagai Penaggulangan Karang Panes}

Yan hana tabwan sirah, tabwan kulit mwang nyawan, ring salu, ring pahumahan, ring kubwan, pateh panese. Yan ring lumbung, ring kamulan hayu ika. Muwah yan hana ingon - ingon, patik, wenang - wenang, salu rupa wetune, panes karang ika, wenang rarung ka segara, tugel gulena, kawandaniya rewekan ring rwi walatung, talining dening budur, bwangen ring payonidi. Raris glarana Panca Tawur.

Artinya jika ada tawon atau lebah bersarang di rumah, begitupula jika ada binatang yang lahirnya berbeda wujud itu disebut dengan Karang Panes. Untuk menetralisirnya harus melaksanakan upacara yang disebut dengan panca tawur yaitu upacara sejenis caru yang lebih besar atau disebut dengan caru panca sata. Di samping itu binatang yang lahirnya berbeda wujud tersebut harus dibuang ke laut. Ini mengandung makna membuang segala kekotoran yang ada di pekarangan.

\subsubsection{Caru Penganggihan Sebagai Penanggulangan Karang Panes}

Di dalam lontar Bhama Kretih disebutkan sebagai berikut.

Iki Caru Panganggihan nga, yan ring karang paumahan karasa panes, maka cihna ing Karang panes yania; katiben kagringan tan pantara mwang kasusupan dening branti, ngimur - imur kalanan mwang sering kna wicara, manusania tan renga ring gagaman manusa. Yan mangkana cihnania, wenang hacaru ring pakarangan, lwirnia; ngadegang sanggar tutwan, munggah banjotan kelanan mwang 
canang lenghawangi, buratwangi, canang gantal. Ring sor ithik bulu sikep, hinolah hurap bang putih jajatah dadi 33 tanding, walulangnia winangun hurip, hangkebang ring caru ika. Ring sanggah kamulan ngaturang prayascita lewih malih nunas pakuluh pamuput caru ika. Ring natar genah carune, madhatengan ayam putih hingolah dadi 5 tanding, saha canang daksina, panyeneng. Di hulun dhatengane, banjotan kelanan, wusan maprayascita ring sanggah raris kepakubonan maprayascita. Yan wus puput ika, buncal ring pempatan agung.

Dalam lontar Bhama Kretih seperti seperti disebutkan di atas bahwa yang di sebut dengan caru penganggihan adalah sebuah caru yang digunakan untuk mentralisir pekarangan yang memiliki sifat memanas/Karang panes yang memiliki cirri-ciri penghuninya tertimpa penyakit tanpa sebab dan tanpa ada obatnya, sering terjadi pertengkaran, bingung, marah, dan tidak ingat akan kewajiban dalam hidupanya itu diharapkan melaksanakan caru Karang panes yang disebut dengan caru penganggihan yang terbuat dari itik yang berbulu hitam yang di olah menjadi caru dan harus membuat upacara menyucian dei tempat suci yang dilanjutkan dipekarangan rumah termasuk para penghuni rumah tersebut. Menurut Linggih (wawancara, tanggal: 23 Juli 2016) menyebutkan melaksanakan caru penganggihan adalah untuk menetralisir pekarangan. Lebih lanjut dipaparkan bahwa dalam keluarganya sering terjadi pertengkaran, banyak yang sakit. Lalu memhon petunjuk kepada sulinggih dan disarankan melaksakan upacara caru yang disebut dengan caru penganggihan seperti tersebut di atas. Dengan melaksanakan caru tersebut akhirnya keadaan keluarganya mulai berangsur-angsur baik.

\subsubsection{Caru Karang panes Sebagai Penaggulangan Karang Panes}

Iki Carun Karang Panes, hapa lwire cihnaning Karang Panes, gring luminta tan pegat matemahan pati mwang sarwa aksi sathonia tlas kageringan, kweh pejah, wenang caru ika. Glarakna ring pakarangan, mangdane sampurna ikang sarwa magalak ring pakarangan. Lwiring caru, sa; tumpeng putih hadanan, iwak satha winangun hurip, jajatah calon rateng tan winalik hanut huriping dina mwang rumbah gile, suruh putih hijo, saha canang daksina, pras penyeneng lis, hartha 225. Mwah hana papendheman rontal

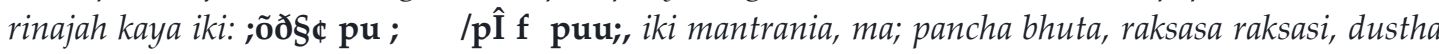
durjana, henduh ta kita, yan tan kita weruh hamaca sastranku; yan sira tan wruh hamaca sastranku, lunghana kita, yan kita wruh palungha kita, tan wruh yen wruh, yen alumuh lungha kita, panger ngke pangraksante ri ngong, hana tadhah sajinta, pulawa sapunggel, susuruh putih hijo, saga rong penek, hayam winangun hurip, rinumbah gile, sasak mentah, jajatah calon tan winalik, twasanta hangraksa hulun. Tlas. Wus angrajah, wus anyaksenana kang caru, pendhemakna rarajahane ring rontal.

Selain caru seperti disebutkan di atas ada caru Karang panes yang ciri-cirinya seperti seluruh binatang peliharaan kena penyakit dan menyebabkan mati maka harus membuat upacara caru Karang panes yang mempergunakan sarana ayam putih di bagi menjadi lima bagian disertai dengan membuat tulisan dalam lontar (rajahan) yang pada akhir upacara lontar yang ditulisi (dirajah) ditanam di pekarangan, dan disertai dengan mantra: pancha bhuta, raksasa raksasi, dustha durjana, henduh ta kita, yan tan kita weruh hamaca sastranku; yan sira tan wruh hamaca sastranku, lunghana kita, yan kita wruh palungha kita, tan wruh yen wruh, yen alumuh lungha kita, panger ngke pangraksante ri ngong, hana tadhah sajinta, pulawa sapunggel, susuruh putih hijo, saga rong penek, hayam winangun hurip, rinumbah gile, sasak mentah, jajatah calon tan winalik, twasanta hangraksa hulun. 


\subsubsection{Caru Kageringan Penanggulangan Karang Panes}

Malih Carun Karang Kageringan, Karang Panes, karang angker, karang aeng mwang sane ngenahin tan pakala miyegan mawyadi, wenang carunin karang ika. Lwing carunia; syap putih maholah dadi 5 tanding, padha majajatah lembat asem, hurab bang putih sowing, walulange malih winangun hurip, tumpengnia padha madanan, macaru bilang bucuing karang, matanem, layang-layangnia ring tengah tanem. Yan nora carunin, ngimuh ikang kala bhuta kabeh harep hanadhah manyakitin sang adruwe humah, tan manggeh yasania, rahina wengi katadhah hantuk kalan bhatari durgha, yan sampun tawurin, enak tekang sarwa kala bhuta, matemahan hayu sang madruwe humah. Iki mantrania, ma; ih Ki Bhuta Jigramaya, marupa manca warna, kita retuning bhuta kala dengen, hamanak I pamali pulung raksa, I undar - undir, eka dasa rowang ira, kita hanggawe kapanjingan hyang lalah, kasandering glap, katiben hamuk, kalebon hamuk, kasiratin rah, salwiring cunthaka bhaya, kapunah den ira sang bhuta jigramaya. Om am ksama sampurna ya namah, sa ba ta a i na ma si way a, om am um mam.

\subsubsection{Caru Rsi Ghana Sebagai Penanggulangan Karang Panes}

Caru Rsi Ghana sangat sering dilaksanakan oleh umat Hindu yang ada di Bali. caru ini biasanya dilaksanakan pada nsaat ada upacara besar seperti upacara ngenteg linggih atau pada saat pelinggih atau pura selesai dipugar. Caru Rsi Ghana bertujuan untuk menyucikan areal tempat suci atau pekarangan. Tujuan caru Rsi Ghana adalah menstanakan Dewa Ghana yaitu Dewa penghalau segala rintangan, agar areal dan penghuninya mendapatkan keselamatan bebas dari pengaruh negatif.

Menurut Bangli (2006: 58) meyebutkan...Iki tingkahing Caru Rsi Ghana maka pemarisudaning karang angker, muang Karang Panes..... artinya ini yang disebut dengan caru Rsi Ghana bertujuan untuk menyucikan areal yang angker atau yang disebut dengan Karang Panes. Berdasarkan hal tersebut sejalan dengan Wikarman (1998: 36) yang menyebutkan bahwa caru Rsi Ghana adalah caru yang tergolong tingkatan madya (menengah) dengan tujuan menghadirkan Dewa Ghana sebagai dewa penghalau segala rintangan untuk menwujudkan keharmonisan.

Dalam lontar Bhama Kretih disebutkan sebagai berikut: ....Nihan Kaputusan Sang Hyang Resi Ghana, pamarisudhaning karang hangker salwiring panes. Yan mati salah pati, kalebon amuk, sinambering glap makrana sang adrewe humah kabhaya - bhaya kojarania, caru iki glarakna ring pomahan ring sanggar ring parhyangan mwang ring tegal sawah sagenahing Karang Panes, aheng mwang hangker, yadnya kapanjingan bhuta kala dengen, umahing dete, caru iki glarakna (maksudnya caru Rsi Ghana). Dari isi lontar tersebut di atas bahwa untuk menanggulangi Karang panes maka diharapkan membuat upacara yang disebut dengan Caru Rsi Ghana, dengan tujuan untuk menetralisir areal pekarangan tersebut agar terhindar dari pengaruh negative.

\subsection{Pandangan Masyarakat Hindu Bali Tentang Karang Panes}

\subsubsection{Pandangan Teologi}

Ajaran agama menuntun manusia untuk melaksanakan suatu kewajiban (swadharma) yang salah satunya adalah memuja Tuhan beserta manifestasi-Nya. Di dalam ajaran agama 
Hindu pemujaan terhadap Tuhan merupakan suatu kewajiban yang mutlak, karena Tuhan disamping sebagi sumber yang utama dan yang paling sempurna serta patut di yakini oleh seseorang yang beragama. Pemujaan terhadap Tuhan merupakan implementasi dari ajaran agama Hindu yaitu Panca Sradha, yang mengandung arti lima keyakinan yang harus dipahami dan dilaksanakan oleh umat Hindu. Salah satunya adalah keyakinan terhadap Tuhan (Brahma Tattwa).

Setiap agama mempunyai teologi masing-masing karena teologi sangat diperlukan di dalam menghayati keberadaan Tuhan. Agama Hindu yang berdasarkan kitab suci Veda meyakini bahwa Tuhan adalah satu-satunya kesempurnaan di jagat raya ini. Kata teologi berasal dari bahasa Yunani yaitu berasal dari kata "Theos dan Logos". Theos mengandung arti Tuhan, dan Logos mengandung arti ilmu. Jadi teologi mengandung arti ilmu yang mempelajari tentang Tuhan (Astina, 2008: 105). Di dalam bahasa Sansekerta teologi disamakan dengan Brahma Widya, di mana Brahma Widya berasal dari dua kata yaitu Brahma dan Widya. Brahma artinya Tuhan, sedangkan Widya artinya pengetahuan. Jadi Brahma Widya artinya pengetahuan tentang Tuhan.

Jika dilihat secara mendalam bahwa agama Hindu memiliki faham kepercayaanyang paling kuno dan yang modern. Tidak ada satu isme pun yang tidak ada di dalam Hinduisme. Ia adalah cikal bakal isme yang ada di dunia ini (Donder, 2006: 110). Kepercayaan yang paling kuno yang dimaksud adalah adanya sebuah kepercayaan seperti konsep ke-Tuhanannya yaitu:

1. Animisme yaitu suatu kepercayaan atau keyakinan bahwa semua benda memiliki roh atau jiwa. Sampai saat ini umat Hindu terutama yang ada di Bali masih menaruh keyakinan yang sangat tinggi terhadap hal tersebut di atas yaitu dengan dibuktikannya adanya upacara terhadap alam seperti Tumpek Uduh/Wariga (upacara untuk tumbuh-tumbuhan), Tumpek Uye (upacara untuk binatang piaraan), Tumpek Landep (upacara segala benda yang berbentuk senjata).

2. Dinamisme yaitu suatu kepercayaan atau keyakinan bahwa semua benda memiliki kekuatan yang bersifat gaib. Di dalam Brhadaranyaka Upanisad II.5.15, menyebutkan:

Sa va ayam atma sarvesam bhutanam adhipatih, sarvesam bhutanam raja,

tad yatha-nabhau ca ratha nemau carah sarve samarpitah. evam evasminn atmani sarvani bhutani sarve devah sarve lokah sarve pranih sarve eta atmanah samarpitah

Terjemahannya:

Sesungguhnya roh itu mengusai semua benda, roh adalah raja dari semua benda, sebagai halnya semua jari-jari roda itu disatukan di dalam sumbu roda dengan rodanya, demikian juga halnya roh dari semua benda, semua dewa, semua alam, semua makhluk hidup, semuanya dalam suatu kesatuan Yang Maha Besar (Donder, 2006: 145-146).

Dari pemaparan di atas sangat jelas bahwa unsur kepercayaan terhadap benda yang memiliki kekuatan bagi masyarakat Hindu Bali masih sangat kental pengaruhnya sampai saat 
ini. Hal ini dapat dibuktikan dengan adanya berbagai bentuk pemujaan Tuhan beserta manifestasinya baik yang distanakan pada padmasana, meru, Pengeluarah, ataupun Padma Andap atau Padma Capah dipercaya memiliki kekuatan gaib yang sangat tinggi, di mana kekuatan tersebut dimaknai sebagai kekuatan Tuhan itu sendiri.

3. Politeisme yaitu suatu keyakinan atau kepercayaan kepada banyak Tuhan. Menurut Donder (2006: 149-150) memberikan penjelasan tentang Politeisme di mana munculnya difinisi tentang Politeisme diakibatkan oleh kerancuan pemahaman oleh para peneliti agama terhadap konsep ke-Tuhanaan. Max Muller sebagai ahli agama-agama tingkat dunia yang meneliti agama Hindu paling awal mengakui kesalahannya terhadap agama Hindu. Max Muller terlanjur menyebut agama Hindu adalah agama yang Politeisme, namun setelah diteliti lebih lanjut ternyata agama Hindu tidak menganut fahan Politeisme tetapi menganut faham

Monoteisme. Hal ini disebabkan oleh tidak semua bahasa Sansekerta dapat diterjemahkan langsung kedalam bahasa Inggris atau bahasa asing lainnyan. Politeisme yang diartikan banyak menyembah para Dewa. Agama Hindu memang benar meyembah banyak para Dewa seperti Dewa Siwa, Wisnu, Brahma, termasuk yang berstanan di Padma Andap yaitu Sang Hyang Durgha Manik, ini bukan berarti banyak menyembah Tuhan. Para Dewa adalah sinar suci dari Tuhan itu sendiri. Karena Tuhan serba maha maka beliau dapat bermenifestasi seperti apa yang ada dalam pikiran penyembahnya dan justru dengan memberikan batasan kepada Tuhan yang tidak terbatas maka membuat Tuhan yang serba maha menjadi terbatas.

4. Panteisme yaitu suatu kepercayaan bahwa segala yang ada di dunia atau alam ini merupakan bagian dari Tuhan. Karena merupakan bagian dari Tuhan maka umat Hindu menginplementasikannya di dalam ajaran agama yaitu dalam konsep ajaran Tri Hita Karana yang ke tiga, yaitu hubungan manusia dengan alam, denan cara memelihara kelestarian alam dan lingkungan. Menurut ajaran agama Hindu alam semesta ini merupakan PrakertiNya. Tuhan meresapi segala ciptaannya baik Bhuana Agung maupun Bhuana Alit, sehingga dengan melestarikan dan memelihara alam sudah melaksanakan yajna seperti Dewa Yajna dan Bhuta Yajna.

5. Totemisme yaitu suatu keyakinan terhadap binatang keramat yang dangat dihormati, di mana binatang tersebut diyakini memiliki kekuatan atau kesaktian, sehingga binatang tersebut dipakai sebagai simbol dalam agama Hindu seperti Lembu, Naga, dan sebagainya.

6. Monoteisme yaitu suatu kepercayaan bahwa Tuhan adalah satu tidak ada duanya. Ini merupakan faham ke-Tuhanan yang modern yang menurut agama lain paling benar. Di dalam Veda sebenarnya faham ini telah ada dan telah disebutkan dengan berbagai sloka yang ada di dalam Veda sebagai kitab suci agama Hindu seperti : Eko narayanad na dwitya 'sti kascit (Tuhan itu satu), Ekam sad wiprah vahuda vadanti (Tuhan hanya satu namun orang bijaksana menyebut-Nya dengan banyak nama).

Secara struktur teologi agama Hindu menyembah Tuhan dai dlam dua konsep yaitu Nirguna Brahman dan Saguna Brahman. Tuhan di dalam konsep Nirguna Brahman angat sulit untuk dipahami sehingga Tuhan harus dipahami di dalam konsep Saguna Brahman. Pemahaman Tuhan dalam konsep Nirguna Brahman dapat dilakukan oleh orang-orang yang memiliki pengetahuan spiritual yang tinggi (Jnanin), sedangksn Tuhan di dalam konsep 
Saguna Brahman dapat dilakukan oleh orang yang memiliki pengetahuan spiritual yang rendah (Ajnanin). dari pemaparan di atas jelaslah bahwa pemahaman tentang Tuhan (teologi) mendapatkan tempat yang sama bagi umat Hindu baik yang memiliki tingkat spiritual yang tinggi maupun yang rendah, yaitu sama-sama dapat menghayati Tuhannya, dengan kondisi serta kemampuannya masing-masing.

Pemahaman dengan konsep Saguna Brahman sangat cocok dan relevan dengan orangorang yang masih mempunyai keterikatan dengan kesadaran fisik juga sampai kepada Tuhan, maka diijinkanlah membuat sebuah simbol perwujudan (Nyasa) sebagai sarana untuk membayangkan kehadiran Tuhan. Dari perspektif Saguna Brahman inilah muncul berbagai penggunaan sarana pemujaan seperti: pratima, upasana, patung, gambar-gambar, sesajen, dan berbagai simbol lainnya (Donder, 2006: 114).

Dari pemaparan di atas dalam kontek pemahaman teologi, Tuhan dalam manifestasinya sebagai Sang Hyang Durgha Manik kalau dilihat dalam fungsi teologi mempunyai suatu peranan yang sangat penting, karena Sang Hyang Durgha Manik merupakan perwujudan manifestasi Tuhan untuk melindungi manusia dari unsur-unsur negative. Kepercayaan terhadap Tuhan tidak saja berdasarkan pikiran, perkataan, namun harus diimbangi oleh perbuatan atau perilaku yang mencerminkan ajaran agama. Pemujaan terhadap Tuhan yang bersifat transenden (Nirguna Brahman) sangat sulit dilakukan oleh orang yang memiliki kemampuan spiritual yang rendah. Namun dengan melaksanakan pemujaan, upacar terhadap manifestasi Tuhan manusia myakini Tuhan itu sendiri.

\subsubsection{Pandangan Tentang Angker}

Hidup adalah perjuangan, percaya diri merupakan salah satu jalan untuk mencapai kesuksesan dan akhirnya menemukan kebehagiaan. Kepercayaan diri bisa hilang apabila muncul ketakutan dalam diri. Jika ketakutan muncul dalam diri maka apapun yang ada dilihat tidak sesuai dengan kenyataan. Semua penglihatan dipengaruhi oleh pikiran sehingga pikiran memberikan signal ketakutan dalam diri manusia. Seperti kata angker, begitu mendengar kata angker pikiran telah memberikan signal kepada manusia untuk takut.

Pandangan masyarakat Hindu yang ada di Bali telah didoktrin terhadap hal-hal yang dianggap angker. Yang dianggap angker seperti kuburan, pura, ataupun tempat tempat tertentu yang memiliki dan mengeluarkan vibrasi angker. Masyarakat Hindu Bali jika mendengar kata angker pikirannya langsung tertuju pada objek tersebut. Selain hal tersebut karang serti karang kelingkuhan, kuta kubanda, tumbak tukad, tumbak rurung, namping bale banjar, perempatan, bekas kuburan bagi masyarakat Hindu Bali dianggap angker. Jika ada tanah seperti tersebut sangat dihindari sebagai tempat tinggal karena tergolong angker. Jika sangat terpaksa menempati tempat tersebut maka harus mendirikan yang disebut dengan palinggih Indra Blaka sebagai penetralisirnya. Karang angker diyakini akan berdampak negatif bagi penghuninya seperti penghuninya tertmipa sakit yang tanpa sebab, binatang piaraan yang mati secara tiba-tiba, dan sering terjadi pertengkaran diantara penghuni.

Catatan

\section{Simpulan}


Berdasarkan pembahasan dari permasalahan di atas penulis dapat memberikan kesimpulan sebagai berikut:

1. Yang disebut dengan karanga panes adalah suatu areal yang memiliki sifat negative menurut Lontar Bhama Kretih. Karang panes dapat memberikan pengaruh negative bagi para penghuninya seperti, sakit yang tidak dapat disembuhkan secara medis, sering terjadi pertengkaran dalam keluarga, binatang piaraan tertimpa penyakit dan menyebabkan kematian. Yang tergolong Karang panes seperti : karang kelingkuhan, karang kuta kubanda, sula nyupi, tumbak rurung, tumbak tukad, nampih bale banjar, namping pempatan, ngulonin pura, karang yang dberdiri di atas tanah kuburan. Selian dari areal Karang panes dapat disebabkan oleh tumbuhan seperti pohon enau yang bercabang, pohon kelapa yang bercabang. Karang panes juga dapat disebabkan oleh binatang sepertri binatang yang beranak hanya satu (manak tunggal). Untuk menetralisir atau menggulangi Karang panes diharapkan membangun palinggih yang disebut dengan palinggih Indra Blaka atau Padma Andap sebagqai sthana Sang Hyang Indra Blaka. Selain berbentuk palinggih juga dalam bentuk ritual seperti Caru seperti caru Karang Panes, caru penganggihan, panca tawur, caru Rsi Ghana.

2. Pandangan masyarakat Hindu Bali tentang Karang panes yaitu pandangan Teologi. Dalam kontek pemahaman teologi, Tuhan dalam manifestasinya sebagai Sang Hyang Durgha Manik kalau dilihat dalam fungsi teologi mempunyai suatu peranan yang sangat penting, karena Sang Hyang Durgha Manik merupakan perwujudan manifestasi Tuhan untuk melindungi manusia dari unsure-unsur negative. Pandangan Angker yaitu Karang angker diyakini akan berdmpak negative bagi penghuninya seperti penghuninya tertimpa sakit yang tanpa sebab, binatang piaraan yang mati secara tiba-tiba, dan sering terjadi pertengkaran diantara penghuni.

\section{DAFTAR PUSTAKA}

Bangli, IB.Putu. (2006). Warnaning Sesayut Lan Caru. Surabaya: Paramita

Dwijendra, Ngakan Ketut Acwin. (2009). Arsitektur dan Kebudayaan Bali Kuno. Denpasar: Udayana University Press.

Dwitayasa, I Made. (2008). Fungsi Caru Rsi Gana dalam prosesi Mlaspas Parahyangan di Desa Pakraman Bayad, Kedisan Tegallalang (Kajian Bentuk, Fungsi, dan Makna), Gianyar. Denpasar: Skripsi IHDN

Dwitayasa, I Made. (2010). “Pemujaan Dewi Danu Di Pura Pucaksari Desa Pakraman Bayad Kedisan Tegallalang Gianyar. Denpasar: Tessis IHDN. Denpasar

Paketan, Ida Bagus Anom. (2005). Membangun Karang Paumahan Menurut Adat, Budaya, dan Agama Hindu. Denpasar: CV. Kayumas Agung

Palmer, Richard E. (2005). Hermeneutika Teori Baru Tentang Interpretasi. Yogyakarta: Pustaka Pelajar. 
Suadia, I Wayan, (2008). "Konsep Ketuhanan Dalam Kitab Siva Purana. Denpasar". Skripsi Fakultas Brahma Widya IHDN. Denpasar.

Sugiyono. (2006). Metode Penelitian Kuantitatif, Kualitatif dan RED. Bandung: Alfabeta.

Suhardana, KM. (2009). Bhama Kretih Penyucian Pekarangan Panes Berbagai Caru dan Sarananya. Surabaya: Paramita

Suharsini-Arikunto. (2006). Prosedur Penelitian. Jakarta : PT Rineka Cipta.

Tim Penyusun Kamus. (1995). Kamus Besar Bahasa Indonesia Edisi Kedua. Jakarta: Balai Pustaka. Donder, I Ketut. (2006). Brahma Vidya Teologi Kasih Semesta. Surabaya: Paramita

Wikarman, I Nyoman Singgin. (1998). Caru Palemahan dan Sasih. Surabaya: Paramita

http://lyanasikumbang.blogspot.co.id/2013/03/pengertian-tujuan-dan-fungsi-penelitian.html

diakses tgl 23 sept. 2016

https://paduarsana.com/tag/karang-panes/diakses tanggal 2 Agustus 2016)

http://suryadistira.blogspot.co.id/2008/05/apa-ciri-ciri-karang-panes.html) 